\title{
The frequency and spectrum of birth defects among 486 longlivers from Ivano-Frankivsk region (West Ukraine)
}

\author{
Kozovyi $\mathbf{R}^{1 *}$, Kovalchuk $\mathrm{L}^{1}$ and Kitsera $\mathbf{N}^{1,2}$ \\ ${ }^{1}$ Ivano-Frankivsk National Medical University, Ukraine \\ ${ }^{2}$ Institute of Hereditary Pathology, National Academy of Medical Sciences of Ukraine", Lviv, Ukraine
}

\begin{abstract}
Birth defects (BD) have a significant impact on the health and further development of the child and its adaptation in society.

The purpose of this study was to document the epidemiological features of BD in longlivers from Precarpathian region (West Ukraine).

Methods: cytogenetic, clinical, genealogical.

Results: The medical history of BDs, somatic pathology and karyotyping was observed in 486 longlivers aged 90-102 from Ivano-Frankivsk region (West Ukraine) during 17 years (1998-2014 yy). In the group of 486 longlivers there were 15 (3.1\%) patients with BD which in our study were isolated. The following defects have been diagnosed: cleft lip and cleft palate ( 2 men and 1 female), genital organs ( 1 man) and musculoskeletal system ( 2 men and 9 female). So patients lived for so long and it did not really affect the quality of their lives). In the longlivers prevailed cleft lip with or without palate, syndactyly and congenital complete absence of upper limb and significant difference was found $(\mathrm{p}<0.05)$ in Eurocat.
\end{abstract}

Stable chromosomal aberrations in any longlivers person is not identified. In a group of 15 longlivers with BDs and in the group of 130 longlivers without BDs, there were no significant differences $(p>0.05)$ in the frequency of chromosomal aberrations.

Conclusion Our study also showed that no significantly risk of BDs among longlivers 3.1\% and population of Ukraine $-2.32 \%$ and Eurocat- $2.55 \%$. The spectrum of chromosomal aberrations of the proband with BD and longlivers without BD had no significant difference $(\mathrm{p}>0.05)$ among them.

\section{Introduction}

According to the World Health Organization the term congenital anomaly includes any morphological, functional, biochemical or molecular defects that may develop in the embryo and fetus from conception until birth, present at birth, whether detected at that time or not [1-3]. Birth defects (BD) or congenital anomalies are defined as a structural or chromosomal malformation with a significant impact on the health and development of a child and determine its further contribution to social life. These pathology are a topic covered in the ICD-10-CM (Q00-Q99) [4-6].

Many researchers are concerned that every year an estimated 7.9 million children are born with a serious birth defect, 3.3 million children (under five years) die from birth defects, and 3.2 million who survive may develop a disability later in the life $[1,6,7]$. In Ukrainian population a frequency of birth defects contains $26.83 \pm 0,08 \%$, especially in the Western of Ukraine respectively of $32.56 \pm 0,09 \%$ o [8]. A long-term man is a person older than 90 years [9]. Longevity is a socio-biological phenomenon, characterized by the fact that a person survives to high age boundaries, which significantly exceeds the average life expectancy. In this article, we want to show what are the BD's of life expectancy in Ukraine and what are the BD's of development in them.

The purpose of this study was to document the epidemiological features of birth defects in longlivers from Ivano-Frankivsk region (Ukraine).

\section{Materials and methods}

The medical history of birth defects and somatic pathology was observed in 486 longlivers aged 90-102 from Ivano-Frankivsk region (West Ukraine) and at the underwent karyotyping and followed-up for 17 years (1998-2014) in the Genetic Laboratory of the State Medical University "Ivano-Frankivsk National Medical University", Ukraine. The examination was carried out on the basis of the Central City Clinical Hospital and of the Regional Clinical Cardiology Clinic in Ivano-Frankivsk, further observation was carried out outpatient.

The familial history in each proband's was reported by themselves and their relatives in response to a standardized self-administered questionnaire. Our study were conducted in compliance with the main provisions of the GCP (1996), the Council of Europe Convention on Human Rights and Biomedicine of 04.04.1997, the Helsinki Declaration, Orders of the Ministry of Health of Ukraine.

Each person before the study has signed an informed consent to the collection of clinical and genealogical data, medical history, anamnesis of life and cytogenetic analysis. 486 long-lived consent was obtained. In

${ }^{\star}$ Correspondence to: Kozovyi R, Ivano-Frankivsk National Medical University, Ukraine, E-mail: ruslan_kozoviy@ukr.net, nkitsera@gmail.com

Key words: longlivers, birth defects, cytogenetic characteristic, Ukraine

Received: June 17, 2020; Accepted: July 07, 2020; Published: July 10, 2020 
each longliver signated of informed consent peripheral blood was taken according to the signed consent.Data about each patient was entered into a specially designed card. All informed consent was verified by the ethics committee of the Ivano-Frankivsk National Medical University (Ukraine).

The exclusion criteria included the patients with cancer and mental illness. We have studied for each of the longliver such indicators as age at diagnosis of $\mathrm{BD}$, age at the time of the study, medical history and karyotype. A clinical history was also recorded for each patient.

To study the peculiarities of karyotype in longlivers, the samples of 15 probands with birth defects and 130 longlivers without these pathology were created taking into account their desire and health at the time of blood collection.

Peripheral blood was used for cytogenetic analysis. For this purpose, five milliliters of peripheral blood was collected in a sterilized syringe under aseptic conditions. The rest of the blood was transferred to the heparin vial. Cytogenetic karyotype was analyzed on leukocytes cultured from human peripheral blood.Over 30 metaphases was analyzed through GTG banding with 450- 550 band resolutions with a microscope (Axiostar plus, Carl Zeiss, Germany) [10]. According to the standard protocol cytogenetic analyzes were performed on lymphocytes stimulated with phytohemagglutinin $[11,12]$.

\section{Results}

Ivano-Frankivsk region is also often called as Prykarpattia is in Western of Ukraine. The peculiarity of this area is that it is located between two tectonic plates Carpathian fold belt and Volynia-Podillya plate. In the Ivano-Frankivsk region there are Carpathian Mountains and one of the largest rivers of Ukraine flows - Dnister [13].

In Ivano-Frankivsk region (West Ukraine) according to the Statistical Office on January, 2018 population [14] was 1,377,496 persons, including 727,318 women (52.8\%).

Among 486 longlivers were 164 male and 322 female (1:2). Patients' age ranged from 90 to 102 years (median $94.8 \pm 4.5$ years), and the longlivers with $\mathrm{BD}$ were 92 to 98 years old (median $95.2 \pm 3.1$ years). There no significant difference was found with regard to the age among longlivers without and with birth defects ( $\mathrm{p}>0.05)$.

In the group of 486 longlivers there were 15 (3.1\%) patients with BD (Table 1). Birth defects in our study was isolated. So patients lived for so long and it did not really affect the quality of their lives. Among 11 codes of Congenital malformations, deformations and chromosomal abnormalities in the ICD-10-CM (Q00-Q99) only three codes: Q35-Q37 - cleft lip and cleft palate, Q50-Q56 - congenital malformations of genital organs, Q65-Q79 - congenital malformations and deformations of the musculoskeletal system predominate in the longlivers.

Among longlivers in our study females were more affected of BD than males (10:5) as 2:1. Age of onset was the presentation in infant. Clinical features in longlivers were concern such systems and part of the bodies: cleft lip and cleft palate ( 2 men and 1 female), genital organs (1 man) and musculoskeletal system ( 2 men and 9 female).

The spectrum of congenital malformations and deformations of the musculoskeletal system in the longlivers proband included polydactyly ( 5 female), syndactyly ( 1 men and 1 female), congenital complete absence of upper limbs (2 female), congenital dislocation of unspecified hip ( 1 female) and congenital pes planus ( 1 man). From the words of patients, these congenital malformations and deformations of the musculoskeletal system did not prevent them from active lifestyles, work and engage in favorite affairs. Woman aged 96 with congenital complete absence of left upper limb could adapt to homework and even embroider. However, woman aged with 93 congenital complete absence of right upper limb always felt that she was not like all the children, so even in the summer, in the heat, she wore clothes on a long sleeve that covered the defect.

The polydactyly of the fingers of the right leg was diagnosed in a woman aged 95 . This same diagnosis was made by father and grandfather proband, who lived until 90 and 87 years respectively. Since this disease is inherited by the autosomal dominant type, the same pathology was found in the son and grandson of proband (Figure 1). In this family there are six relatives with this pathology, because the same diagnosis had the grandfather's son proband on the line of his father. Only a grandson of proband was operated due to polydactyly in childhood, now he is 48 years old. Another relatives, as noted by a longlived woman, lived fully with this pathology, only had to order wider shoes for comfortable walking.

In the longlivers from Precarpathian region (West Ukraine) prevailed cleft lip with or without palate, syndactyly and congenital complete absence of upper limb and significant difference was found $(\mathrm{p}<0,05)$ in Eurocat.

Table 1. The frequency of birth defects among longlivers from Ivano-Frankivsk region (West Ukraine)

\begin{tabular}{|c|c|c|c|c|c|c|c|}
\hline \multirow{2}{*}{$\begin{array}{c}\text { ICD-10-CM } \\
\text { Diagnosis Code }\end{array}$} & \multirow{2}{*}{ Birth defects } & \multicolumn{2}{|c|}{ Ivano-Frankivsk region } & \multicolumn{2}{|c|}{ Ukraine } & \multicolumn{2}{|c|}{ Eurocat } \\
\hline & & $n=486$ & $\%$ & per 10,000 births & $\%$ & per 10,000 births & $\%$ \\
\hline Q37.1 & $\begin{array}{l}\text { Cleft hard palate with unilateral cleft } \\
\text { lip }\end{array}$ & 1 & $0.2^{*}$ & 4.27 & 0.04 & 14.16 & 0.14 \\
\hline Q37.9 & Cleft lip with or without palate & 2 & $0.4 * 0$ & 9.13 & 0.09 & 8.36 & 0.08 \\
\hline Q54.9 & Hypospadias & 1 & 0.2 & 21.55 & 0.22 & 17.82 & 0.18 \\
\hline Q65.0 & $\begin{array}{l}\text { Congenital dislocation of unspecified } \\
\text { hip, unilateral }\end{array}$ & 1 & 0.2 & 13.01 & 0.13 & 11.39 & 0.11 \\
\hline Q66.5 & Congenital pes planus & 1 & 0.2 & 10.19 & 0.1 & 11.48 & 0.12 \\
\hline Q69.9 & Polydactyly & 5 & $1.0 * 0$ & 12.88 & 0.13 & 9.70 & 0.1 \\
\hline Q70.1 & Syndactyly & 2 & $0.4 * 0$ & 3.81 & 0.04 & 4.02 & 0.04 \\
\hline Q71.01 & $\begin{array}{c}\text { Congenital complete absence of right } \\
\text { upper limb }\end{array}$ & 1 & $0.2^{* o}$ & & & & \\
\hline \multirow[t]{2}{*}{ Q71.02 } & $\begin{array}{l}\text { Congenital complete absence of left } \\
\text { upper limb }\end{array}$ & 1 & $0.2 *^{\circ}$ & 5.52 & 0.05 & 5.55 & 0.05 \\
\hline & All Anomalies & 15 & 3.1 & 232.03 & 2.32 & 255.61 & 2.55 \\
\hline
\end{tabular}

Note. *the probability of differences with the indicators of birth defects in newborns in Ukraine $(\mathrm{p}<0,05)$.

${ }^{\circ}$ the probability of differences with the indicators of birth defects in newborns in Eurocat $(p<0,05)$. 


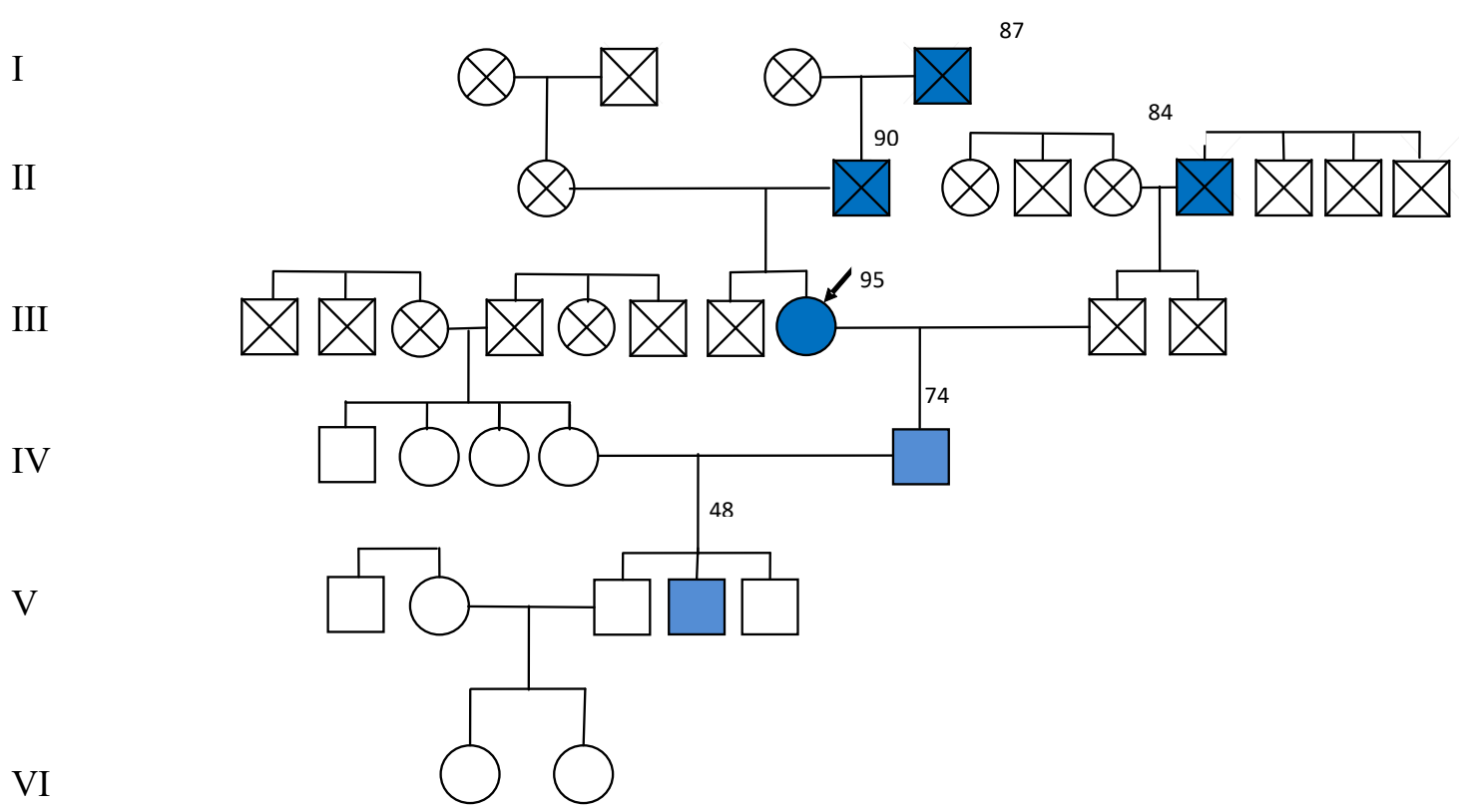

Figure 1. Family tree of female aged 95 with polydactyly in proband and relatives from Verkhovyna of Ivano-Frankivsk region (West Ukraine)

$\square$ - polydactyly

Cleft hard palate with unilateral cleft lip significantly more frequently encountered $(\mathrm{p}<0,05)$ among longlivers only in Ukraine.

By contrast hypospadias, congenital dislocation of unspecified hip and congenital pes planus (Table 1$)$ no significant difference $(p>0.05)$ was found among longlivers from Precarpathian region in comparison with the data of Ukraine and Eurocat.

Our research showed a birth defects of longlivers of 3.1 per 100 live births with predominance of congenital malformations and deformations of the musculoskeletal system - 11 (73.3\%) cases from 15 longlivers with birth defects. Our study also showed that no significantly risk among longlivers $3.1 \%$ and population of Ukraine $-2.32 \%$ and Eurocat- $2.55 \%$ [15].

As a result of the cytogenetic analysis of 1025 metaphase plates in a group of 15 longlivers with $\mathrm{BD}$ and 6678 metaphases in the group of 130 longlivers without congenital anomalies, there were no significant differences $(\mathrm{p}>0.05)$ in the frequency of chromosomal aberrations between the two groups studied. In longlivers with BD and healthy longlivers, the overall rate of chromosomal aberrations was $2.21 \pm 0.31$ and $2.17 \pm 0.46$, respectively ( $p>0.05$ ). Stable chromosomal aberrations in any longlivers person is not identified. The spectrum of chromosomal aberrations of all longlivers was dominated by single fragments: $1.33 \%$ and $1.29 \%$ in the proband with $\mathrm{BD}$ and longlivers without $\mathrm{BD}(\mathrm{p}>0.05)$.

Among the chromosomal aberrations of the chromosomal type, the largest proportion of paired fragments was found - in the group of 15 long-livers with $\mathrm{BD}$ it was $0.89 \%$, in healthy longlivers - $0.81 \%$ $(p>0.05)$. The analysis of the second indicator of the immunogenetic status, the frequency of associations of acrocentric chromosomes $(A A C)$, does not reveal the probable differences $(p>0.05)$ between the parameters of the frequency of cells with AAC, the average number of AACs in a single cell, and the number of chromosomes associated with a single cell.

\section{Discussion}

Congenital anomalies are a global health problem. Among the studies we have found in accessible world literature a birth prevalence of congenital anomalies is $20-55$ per 1000 live births with significant variation, depending the study design, method of case ascertainment and about the demographics of the population under study [16]. However, there are rare reports of frequency and range of developmental disorders among longlivers.

Our work is one of the most complete and largest studies of $\mathrm{BD}$ prevalence in Ukraine among longlivers.

We believe that this conclusion can be the result of two factors. First, there is a difference major and minor BD [17-19]. The second factor - probands had no other complicated somatic pathology, often they were having a healthy lifestyle. They were believers and hoped that life would endow them with other caresses.

The frequency of BDs has been well investigated and previously indicated in several studies $[20,21]$. However, in our study there are certain features, that distinguish it from other research. The first aspect, we investigated the frequency of BDs among longlivers in Ukraine, in particular from Precarpathian region (West Ukraine).

It is very important for society and medical practice to evaluate epidemiological data on the prevalence of DB among longlivers.

Our data will enhance and complement the data of other publications $[22,23]$. Second, we used hospital registry data, which allowed us to survey more patients. Third, our sample of longlivers is one of the largest in Ukraine, which makes studying the frequency of $\mathrm{BDs}$ very important for further research in other regions of the country.

Studying the frequency of BDs can suggest the impact of teratogens and mutagens and avoid their effects when planning further pregnancies, conducting medical genetic counseling in individuals at high risk for developmental disabilities. Nevertheless, published 
comprehensive data about the prevalence of birth defects are scarce in European countries including Ukraine.

\section{Conclusion}

Our study also showed that no significantly risk of BDs among longlivers $3.1 \%$ and population of Ukraine $-2.32 \%$ and Eurocat- $2.55 \%$. The spectrum of chromosomal aberrations of the proband with $\mathrm{BD}$ and longlivers without BD had no significant difference ( $p>0.05)$ among them.

\section{References}

1. Shi Y, Zhang B, Kong F, Li X (2018) Prenatal limb defects: Epidemiologic characteristics and an epidemiologic analysis of risk factors. Medicine 97: e11471.

2. Guidelines for the study of genetic effects in human populations. Geneva, World Health Organization; 1985 (Environmental Health Criteria No. 46). http://www.inchem.org/ documents/ehc/.

3. Shawky RM, Sadik DI (2011) Congenital malformations prevalent among Egyptian children and associated risk factors. The Egyptian Journal of Medical Human Genetics 12: 69-78.

4. Anderka M, Mai CT, Judson EM, Langlois PH, Lupo PJ, et al. (2018) Status of population-based birth defects surveillance programs before and after the Zika public health response in the United States. Birth Defects Research 19: 1388-1394.

5. Wang H, Barisic I, Loane M, Addor MC, Bailey LM, et al. (2019) Congenital clubfoot in Europe: A population-based study. Am J Med Genet A 179: 595-601.

6. International classification of diseases, tenth revision, clinical modification (ICD10-CM). Congenital malformations, deformations and chromosomal abnormalities. https://www.icd10data.com/ICD10CM/Codes/Q00-Q99.

7. Carmona RH (2005) The global challenges of birth defects and disabilities. Lancet 9492: 1142-1144.

8. Lanovenko EG (2018) Prevalence of congenital pathology in populations with different genetic and de-mographic structure. Studia Biologica 12: 45-52.

9. Perls T, Levenson R, Regan M, Puca A (2002) What does in take to live to 100 ? Mech Ageing Dev 123: 231-242.
10. Moorhead PS, Nowell PC, Mellman WJ, Battips DM, Hungerford DA (1960) Chromosome preparations of leukocytes cultured from human peripheral blood. Exp Cell Res 20: 613-616.

11. Shaffer LG, McGowan-Jordan J, Schmid M (2013) ISCN 2013- An international system for human cytogenetic nomenclature (2013). Karger.

12. Seabright M (1971) A rapid banding technique for human chromosomes. Lancet 2: 971-972.

13. Ivano-Frankivsk_Oblast. http://resource.history.org.ua.

14. Population of Ivano-Frankivsk. www.ifstat.gov.ua.

15. http://www.eurocat-network.eu/accessprevalencedata/prevalencetables

16. Canfield MA, Mai CT, Wang Y, O'Halloran A, Marengo LK, et al. (2014) The association between race/ethnicity and major birth defects in the United States, 19992007. AJPH 104: e14-e23.

17. Piette N, Zambelli PY, N'Dele D (2017) Isolated heptadactylia: A case report of central polydactyly of the foot. Medicine 96 : e8324.

18. Rodríguez-Hernández JL, Rodríguez-González F, Riaño-Ruiz M, Martínez-Quintana E (2018) Risk factors for hyperuricemia in congenital heart disease patients and its relation to cardiovascular death. Congenit Heart Dis 13: 655-662.

19. Michaudet C, Edenfield KM, Nicolette GW, Carek PJ (2018) Foot and ankle conditions: Pes planus. FP Essent 465: 18-23.

20. McDonald CL, Bennett CL, Rosner DK, Steele KM (2019) Perceptions of ability among adults with upper limb absence: impacts of learning, identity, and community. Disabil Rehabil Disabil Rehabil 18: 1-10.

21. Fudalej PS, Urbanova W, Klimova I, Dubovska I, Brudnicki A, et al. (2019) A threecenter study of the outcome of treatment of cleft lip and palate. Part 2: Dental arch relationships. J Craniomaxillofac Surg.

22. Parker SE, Mai CT, Canfield MA, Rickard R, Wang Y, et al. (2010) Updated nationa birth prevalence estimates for selected birth defects in the United States, 2004-2006. Birth Defects Research (Part A) Clin Mol Teratol 88: 1008-1016.

23. Ortiz-Cruz G, Luna-Muñoz L, Arteaga-Vázquez J, Mutchinick OM (2019) Isolated postaxial polydactyly: Epidemiologic characteristics from a multicenter birth defects study. Am J Med Genet A.

Copyright: $\odot 2020$ Kozovyi R. This is an open-access article distributed under the terms of the Creative Commons Attribution License, which permits unrestricted use, distribution, and reproduction in any medium, provided the original author and source are credited. 